\title{
Effects of Locus Coeruleus Lesions on Auditory, Long-Latency, Event-Related Potentials in Monkey
}

\author{
J. A. Pineda, ${ }^{1}$ S. L. Foote, ${ }^{2,4}$ and H. J. Neville ${ }^{1,3}$ \\ Departments of 'Neuroscience and ${ }^{2}$ Psychiatry, University of California, San Diego, La Jolla, California 92093, ${ }^{3 T h e}$ Salk \\ Institute, and ${ }^{4}$ Scripps Clinic and Research Foundation, La Jolla, California 92037
}

\begin{abstract}
It has previously been demonstrated that monkeys exhibit certain event-related potential (ERP) components showing latency, polarity, and contingency similarities to those observed in humans. In the present study, monkey P300-like components were studied in order to evaluate the hypothesis that the noradrenergic locus coeruleus (LC) system participates in their generation or modulation. ERPs were recorded from untrained squirrel monkeys (Saimiri sciureus) twice a week for 4 weeks before and after bilateral LC lesions and interruption of dorsal bundle (DB) fibers. Stimuli consisted of 2 and $6 \mathrm{kHz}$ tone pips (40 msec duration, $60 \mathrm{~dB}$ above $\mathrm{nHL}$ ) presented once a second in random order. In most sessions, one tone constituted $90 \%$ of the stimuli and the other tone $10 \%$, while in some sessions tones were made equiprobable to test the effects of manipulating stimulus probability. LC and DB lesions were made by first localizing the nucleus and creating an electrolytic lesion. Then, the electrode was placed at the anterior pole of the nucleus and a knife cut effected. The extent of damage to LC perikarya and ascending axons was assessed by reconstructing lesions from Nissl-stained sagittal sections through the brain stems. The effect of lesions on cortical noradrenergic axons was immunohistochemically verified utilizing antisera directed against dopamine-B-hydroxylase and tyrosine hydroxylase to label noradrenergic and dopaminergic axons, respectively.
\end{abstract}

The prelesion ERP results replicated previous findings of P300-like components recorded in response to low-probability tones. The postlesion ERP data indicated that following damage to LC cell bodies, combined with interruption of histochemically detectable ascending noradrenergic axons, monkey P300-like potentials exhibited decreased areas, altered brain-surface distribution, and reduced sensitivity to stimulus probability. The correlation between the extent of cell body lesions and percentage reduction in the magnitude of P300-like responses was significant. However, interruption of DB fibers alone did not have similar effects. Neither

\footnotetext{
Received Nov. 3, 1987; revised May 16, 1988; accepted May 17, 1988.

We thank Dr. J. Polich for helpful comments on an earlier draft of this report and T. Holmes for excellent technical assistance. This research was supported by Public Health Service Grant NS21384 (S.L.F.), AFOSR 86-NL-144 (S.L.F.), and Alcohol Research Center Grant AA524061 (H.J.N. and S.L.F.)

The studies reported here represent a portion of J.A.P.'s thesis research for the Doctor of Philosophy degree in Neurosciences, University of California, San Diego, 1987.

Correspondence should be addressed to Jaime A. Pineda, Ph.D., Department of Psychiatry (M-003), University of California, San Diego, La Jolla, CA 92093. Copyright (C) 1989 Society for Neuroscience $0270-6474 / 89 / 010081-13 \$ 02.00 / 0$
}

type of lesion had any effect on amplitudes, latencies, or brain-surface distributions of P52, P172, or N250-900. There was, however, a significant effect on N106. Stimulus probability effects on the frontally distributed P52 and N106 were not altered by the lesions. These data support the hypothesis that the integrity of the LC nucleus and its ascending fibers is important in the generation and modulation of surfacerecorded P300-like activity.

Long-latency components of event-related potentials (ERPs) are some of the more intensively studied, noninvasive, electrophysiological correlates of human cognition. Some well-known examples include the positive potentials recorded approximately $300 \mathrm{msec}$ after the occurrence of novel or attentioneliciting events that are embedded in a repetitive background. These P300-like potentials are recorded over wide areas of the scalp with magnitudes that are sensitive to stimulus probability and task relevance (Sutton et al., 1965; Squires et al., 1975; Donchin et al., 1978). One component, P3b, occurs in discrimination tasks following target stimuli that require a motor response. This component is characterized by a distinct centroparietal distribution, long-latency $(300-600 \mathrm{msec})$, and large amplitude $(15-30 \mu \mathrm{V})$. In passive situations, where subjects presumably ignore the stimuli, another P300-like potential, P3a, is evident. It exhibits a frontocentral distribution, relatively earlier latency (220-280 msec), and smaller amplitude (Ritter et al., 1968; Squires et al., 1975; Roth et al., 1976). P3a is usually associated with novelty detection and orienting, while $\mathrm{P} 3 \mathrm{~b}$ has been related to attention, stimulus categorization, and mnemonic processing (for reviews, see Donchin et al., 1978; Hillyard and Picton, 1979; Pritchard, 1981; Hillyard and Kutas, 1983).

In addition to these well-known morphological, topographical, and functional characteristics, systematic changes in P300like potentials have been shown to accompany normal development and aging (Courchesne, 1977, 1978; Squires et al., 1978; Pfefferbaum et al., 1984; Polich et al., 1985). Changes in P300 also occur in patients exhibiting symptoms of depression, alcoholism, dysphasia, schizophrenia, autism, dementia, and psychoses (Callaway, 1975; Roth et al., 1980; Martineau et al., 1984; Diner et al., 1985; Polich et al., 1986). Thus, the reliability of P300-like potentials, their usefulness as indices of cognitive activity, and their use as diagnostic tools for normal brain development and brain dysfunction have made questions regarding their neural origins extremely compelling.

Two lypes of hypotheses regarding the neural origins of P300like potentials, particularly P3b, are evident in the literature: 
those implicating a single neural source whose field potentials are volume conducted throughout large regions of the brain and those suggesting the existence of multiplc, independent sources. Single-source hypotheses have been challenged by recent evidence of steep potential gradients and polarity inversions in human P300-like activity recorded intracranially in the frontal cortex (Wood and McCarthy, 1986), as well as in the hippocampus or amygdala (Halgren et al., 1980). These data suggest that P300-like activity is locally generated in several widely separated brain areas. Thus, the alternative view of multiple, active sites is supported by the wide distribution of P300-like potentials recorded intracranially in humans and animals (cingulate cortex: Gabriel et al., 1983; suprasylvian and marginal gyri: O'Connor and Starr, 1985; hippocampus and amygdala: Halgren et al., 1980; Wood et al., 1980; McCarthy et al., 1982; frontal cortex: Wood and McCarthy, 1986; thalamus: Yingling and Hosobuchi, 1984). However, while this alternative hypothesis could account for such a widespread distribution, it does not account for the uniformity of latency at such spatially distributed sites. Nor can it explain the similarity in latency that characterizes P300-like activity recorded in animals (e.g., rat, cat, monkey) whose brains vary widely in size (O'Brien, 1982; Harrison and Buchwald, 1985; Pineda et al., 1987; Paller et al., 1988). Therefore, a modification of the multiple-source proposition would appear to be necessary to formulate a more adequate hypothesis of $\mathrm{P} 300$ generation.

One possibility is that a widely distributed neural system synchronously impacts on a number of areas. While several such candidate systems have been characterized, the noradrenergic (NA) nucleus locus coeruleus (LC) exhibits the anatomic, physiologic, and functional properties (reviewed in Foote et al., 1983) necessary to subserve such a role. The evidence concerning widely divergent LC projections, homogeneous activity of source neurons, and transmitter effects on target neurons suggests that LC is activated during alerting or arousal, which leads to NA release onto target neurons in many brain regions. Recent evidence also indicates that the relatively slow conduction times of LC efferent volleys to distant target areas are conserved across species (Aston-Jones et al., 1986), a factor which may underlie the similarity in P300-like component latencies in different species. Because of these characteristics, one proposed functional role for LC is modulation of the organism's responsivencss to biologically relevant events during the waking state and particularly during periods of increased attentiveness (Aston-Jones et al., 1984; Foote and Morrison, 1987). This hypothesis suggests that novel, surprising, and attention-eliciting events increase LC discharge activity and enhance "attentiveness." We further hypothesize that such a state may be a necessary precondition for the elicitation or enhancement of slow endogenous potentials or may directly produce synchronized slow electrical activity that may be evident as surface-recorded P300-like potentials.

In the studies reported here, the role of NA-LC in generating or modulating P300-like activity was tested by recording ERPs in behaviorally passive monkeys before and after electrolytic LC lesions and/or interruption of ascending noradrenergic dorsal bundle (DB) fibers. To determine the effects of lesions on surface-recorded ERP activity, the following pre- and postlesion mcasures were evaluated: (1) peak amplitudes, areas, and latencies of P300-like potentials; (2) peak amplitudes and latencies of other ERP components; and (3) effects of probability manipulations on the magnitudes of P300-like potentials.

\section{Materials and Methods}

\section{Subjects}

Subjects were 5 adult male Guyanan squirrel monkeys (Saimiri sciureus) approximately $2-4$ years old and weighing $700-1200 \mathrm{gm}$. Monkeys had no previous exposure to experimental auditory stimulation.

\section{Overview of experimental design}

In the initial stage of these experiments, monkeys were surgically implanted with skull screws, which later served to record EEG activity. Following 7-10 $\mathrm{d}$ of recovery, ERPs were recorded from each subject during 2 recording sessions per week for 4 weeks. Then, in a second surgical procedure, bilateral LC lesions and DB knife cuts were created in each monkey. Both types of lesions were made to increase the likelihood that noradrenergic innervation of cortex would be disrupted. After a $10 \mathrm{~d}$ recovery period, identical ERP recording sessions were resumed for 4 weeks. Pre- and postlesion ERPs were compared, and lesion sites and the density of cortical monoamine fibers were anatomically and immunohistochemically evaluated. Finally, post hoc analyses were conducted in which lesion efficacy was correlated with the magnitude of ERP effects.

\section{Surgical procedures}

Electrode implantation. Monkeys were anesthetized with ketamine hydrochloride $(25 \mathrm{mg} / \mathrm{kg})$ and placed in a stereotaxic instrument. For the duration of the surgery, anesthesia was maintained with halothane $(0.5-$ $1.5 \%$ in air). Using aseptic procedures, the skin overlying the dorsal aspect of the skull was resected, the underlying muscles were retracted, and small stainless steel screws ( 00 gauge, $1.5 \mathrm{~mm}$ long) were threaded into burr holes in the skull at locations analogous to those described by the 10-20 International System (see ERP recording protocol below). Wire leads from these electrodes were attached to a multipin connector, and electrodes, wire leads, and connector were affixed to the skull with anchor screws and dental acrylic. Prelesion recording sessions were begun 7-10 d after this surgery.

$L C$ and $D B$ lesions. Aseptic surgical procedures similar to those described above for electrode implantation were utilized. After the skin overlying the dorsal aspect of the skull was resected, a small flap of skull was removed at the appropriate stereotaxic coordinates to permit microelectrode penetrations into the area of the LC (P 1.0, L 2.1). A tungsten microelectrode was utilized for unit recording. Specific physiological landmarks observed during the initial electrode penetration, such as the responsiveness of inferior colliculus neurons to auditory stimulation, guided the exact positioning of further penetrations. The distinctive eletrophysiological characteristics of LC neurons (e.g., slow firing rates, long-duration, initially and largely positive action potentials in the unfiltered trace) were used to verify the positioning of the electrode tip in the nucleus. Once this had been achieved, an electrolytic lesion was created by passing $0.5 \mathrm{~mA}$ of cathodal current for $15 \mathrm{sec}$. In one subject, 2 such lesions were made along the rostrocaudal extent of the nucleus. The electrode was then withdrawn and repositioned at the anterior pole of the nucleus, lowered to a level approximately $1 \mathrm{~mm}$ ventral to the ventral boundary of the nucleus, and moved $1500 \mu \mathrm{m}$ in the mediolateral dimension to effect a knife cut, severing ascending $L C$ axons. Similar procedures were repeated in the other hemisphere. After the electrode was removed, the skull cavity was filled with Gelfoam and covered with dental acrylic.

\section{ERP recording protocol}

During ERP rccording scssions, monkcys were placed in a specially designed primate chair that restricted gross bodily movements but allowed head, arm, and tail movements. A flexible cable was attached to the connector on the monkey's head to record EEG signals from the implanted screw electrodes. These signals were routed to EEG amplifiers via an electrode selector box. Free-field auditory stimuli consisting of 2 and $6 \mathrm{kHz}$ tone pips [ $40 \mathrm{msec}$ duration, $10 \mathrm{msec}$ rise/fall time at 60 $\mathrm{dB}$ above threshold for a normal human (nHL)] were presented once a second in random order through a small speaker centered approximately $20 \mathrm{~cm}$ above the monkey's head. Masking background noise, approximately $45 \mathrm{~dB}$ above $\mathrm{nHL}$, was present throughout the recording session. Two sessions per week for 4 weeks were recorded for each subject prior to lesions, with a similar number of recording sessions following lesions. 
A block of 255 tones was presented per session lasting approximately $20 \mathrm{~min}$. In most sessions, $6 \mathrm{kHz}$ tones constituted $90 \%$ of the trials ("frequent"), while $2 \mathrm{kHz}$ tones occurred $10 \%$ of the time ("infrequent"). Because pilot studies had indicated that lower-pitch tones produced more robust and reliable ERPs, all monkeys were exposed to the lowerpitch tone as the infrequent stimulus. In order to further evaluate the effects of stimulus probability, tones were made equiprobable in some sessions.

EEG activity was recorded from frontal and parietal midline sites $(\mathrm{Fz}$ and $\mathrm{Pz}$ ), from 2 lateral frontal sites (left, F3, right, $\mathrm{F} 4$ ), and from 2 lateral parietal sites (left, P3, right, P4) (see Neville and Foote, 1984, for details of electrode placement). Electro-ocular activity (EOG) was recorded from the right supraorbital ridge. All recordings were obtained using either an inion electrode or linked mastoid electrodes as reference. No relevant differences in ERPs were found using these 2 reference sites. EEG activity was amplified by a Grass model 7D polygraph with 7P5B amplifiers having bandpass limits of 0.15 and $75 \mathrm{~Hz}$. Eight channels of EEG were digitized on-line on a MINC-11/23 computer and stored on disk for later analysis. EEG signals were digitized at a sampling rate of $256 \mathrm{~Hz}$, starting $100 \mathrm{msec}$ prior to and ending $900 \mathrm{msec}$ after stimulus onset. An artifact rejection program was used to exclude trials that exceeded an amplitude of $75 \mu \mathrm{V}$ in the EOG channel.

\section{Data analysis}

Weekly and monthly ERP averages were computed for each monkey for each type of stimulus (frequent and infrequent) before and after lesions. Since preliminary visual inspection of the data indicated that the recorded waveforms resembled those previously reported (Pineda et al., 1987), similar latency windows were utilized to score the specific components at all electrode sites. This included using intervals to score 2 peaks comprising the large positivity in the $200-500 \mathrm{msec}$ range. As noted in the introduction, multiple P300 subcomponents are also normally recorded in humans within this range. Amplitudes and latencies were quantified using computer programs that measured the largest positive $(\mathrm{P})$ or negative $(\mathrm{N})$ peaks relative to $100 \mathrm{msec}$ of prestimulus baseline activity within these intervals. The total integrated area (duration $\times$ mean amplitude) of specified polarity was also determined. The intervals were (1) P52: 10-100, (2) N106: 40-140, (3) P176: 100195, (4) P239: 200-295, (5) P372: 300-450, and (6) N250-900:250900 .

Monthly subject averages were evaluated statistically using analysis of variance (ANOVA) with repeated measures, utilizing the Greenhouse-Geisser correction for degrees of freedom. A 4-way ANOVA with factors of lesion (pre- and post-), block (90-10 and 50-50), probability [infrequent (low pitch) and frequent (high pitch)], and electrodes ( $\mathrm{Fz}$, $\mathrm{Pz}, \mathrm{F} 3, \mathrm{~F} 4, \mathrm{P3}, \mathrm{P4}$ ) was used to assess differences. The effects of repetitive sessions and component asymmetries were analyzed by using week (4) and hemisphere (right and left) as additional factors.

\section{Histology and immunohistochemistry}

Each animal was sacrificed approximately a week after the final postlesion recording session. Animals were deeply anesthetized with ketamine hydrochloride $(25 \mathrm{mg} / \mathrm{kg}$, IM) followed by pentobarbital sodium $(10 \mathrm{mg} / \mathrm{kg}$, IP). After the chest was opened, $1.5 \mathrm{ml}$ of $1 \%$ aqueous sodium nitrite was injected into the left ventricle as a vasodilator. Animals were then perfused transcardially with cold $1 \%$ paraformaldehyde in phosphate buffer $(0.15 \mathrm{M})$ for $0.5-1 \mathrm{~min}$ followed by perfusion with cold $4 \%$ paraformaldehyde in phosphate buffer $(0.15 \mathrm{M})$ for $8 \mathrm{~min}$ at a rate of $300 \mathrm{ml} / \mathrm{min}$. The brains were then rapidly removed, and tissue blocks (3-5 mm) were placed in cold fixative for an additional $1-2 \mathrm{hr}$ and then washed in a series of cold, sucrose solutions. Blocks were sectioned either coronally or sagittally in a cryostat at $40 \mu \mathrm{m}$. To visualize NA axons in the cortex (see Morrison and Foote, 1986), some forebrain tissue sections were incubated with a rabbit antiserum directed against DBH that had been purified from a clonal cell line of human pheochromocytoma (Markey et al., 1980). The anti-DBH antiserum was diluted $1: 3000$ in PBS, pH 7.4, containing $0.3 \%$ Triton X-100 and 0.5 $\mathrm{mg} / \mathrm{ml}$ BSA. Sections from various cortical areas were then processed by the avidin-biotin method of Hsu et al. (1981) using the Vectastain $\mathrm{ABC}$ kit (Vector Laboratories, Burlingame, $\mathrm{CA}$ ) and diaminobenzidine. To visualize dopamine (DA) axons in the cortex, other sections were incubated with anti-tyrosine hydroxylase (TH) diluted 1:1500 (see Lewis et al., 1987, for details). Procedures for TH immunohistochemistry were similar to those described for DBH except that tissue blocks were postfixed for $6 \mathrm{hr}$. Some sections were also stained with cresyl violet for histological examination. One-in-five series of sagittal sections through the brain stem, stained with cresyl violet, were examined with a microscope at a magnification of $6.3 \times$ to quantify the extent of LC damage. Approximately 5-7 sections were examined to cover the entire volume of LC per animal. The video image of the field was displayed on a computer screen and an estimate of the percentage of the LC nucleus that had been lesioned was obtained by determining the area of gliotic tissue relative to the area of the nucleus. This was done by utilizing a digitizing tablet to outline and compute the area for each region separately.

\section{Results}

\section{Prelesion ERPs}

Prelesion ERPs resembled those previously reported for squirrel monkey in this paradigm (Neville and Foote, 1984; Pineda et al., 1987). As illustrated in the grand average (across all subjects) ERPs in Figure 1 and in the individual subject data shown in Figure 2, a large triphasic response centered over midfrontal arcas was cvident in the first $200 \mathrm{msec}$ following either frequent or infrequent tones. This response consisted of a large positivity (mean latency, $52 \mathrm{msec}$ ) followed by a large negativity (mean latency, $106 \mathrm{msec}$ ) and a subsequent positivity (mean latency, $176 \mathrm{msec}$ ). At longer latencies, and most prominently at lateral parietal electrodes, a broad positivity with a bipeaked morphology (mean latencies of 239 and $372 \mathrm{msec}$, respectively) was elicited in response to infrequent tones. A long-duration negativity was also recorded over frontal cortex (N250-900), temporally overlapping with the late positive components and peaking in the 500-600 msec range.

Component distribution. P52, N106, P176, and N250-900 were largest over midfrontal cortex with significant anterior-toposterior gradients along midline electrode sites $(p<0.05)$. In contrast, later potentials, such as $\mathrm{P} 239$, were larger over lateral $(452 \mathrm{msec}-\mu \mathrm{V})$ than midline $(182 \mathrm{msec}-\mu \mathrm{V})$ sites [electrode, $F(5,20)-4.62, p<0.01]$. $\mathrm{P} 239$ responses were also significantly larger at lateral posterior $(658 \mathrm{msec}-\mu \mathrm{V})$ than at lateral anterior electrodes $(246 \mathrm{msec}-\mu \mathrm{V})$ [electrode, $F(3,12)=3.59, p<0.05$ ]. P372 exhibited the same lateral parietal distribution as P239 [electrode, $F(3,12)=8.05, p<0.01$ ].

Probability effects. P52 was significantly larger in response to infrequent (low-pitch) tones $(489 \mathrm{msec}-\mu \mathrm{V})$ than to frequent (high-pitch) tones $(247 \mathrm{msec}-\mu \mathrm{V})$ [probability, $F(1,4)=9.21, p$ $<0.04]$. N106 responses were also larger following infrequent (low-pitch) tones but mainly over midline electrodes [probability $\times$ electrode, $F(5,20)=3.48, p<0.03$ ]. P176 was unaffected by stimulus probability.

P239 responses following infrequent tones in the $90-10$ blocks $(637 \mathrm{msec}-\mu \mathrm{V})$ were significantly larger than responses to frequent tones (349 msec- $\mu \mathrm{V}$ ) [probability, $F(1,4)=18.27, p<$ 0.02 ]. P372 also exhibited similar differential responses to the 2 tones [probability, $F(1,4)=11.29, p<0.03$ ]. In contrast, $\mathrm{P} 239$ and P372 in the 50-50 blocks did not vary significantly in response to the 2 tones. A probability by electrode interaction was also significant for $\mathrm{P} 372$ [probability $\times$ electrode, $F(5,20)$ $=3.63, p<0.02$ ], indicating that the effect was maximal over lateral parietal areas. N250-900 did not exhibit a sensitivity to stimulus probability.

Lateral asymmetries. P239 arca over the right hemisphere in the $90-10$ and $50-50$ blocks tended to be larger $(742 \mathrm{msec}-\mu \mathrm{V})$ than over the left hemisphere $(493 \mathrm{msec}-\mu \mathrm{V})$ [hemisphere, $F(1,4)$ $=7.09, p=0.056]$. P372 exhibited a similar asymmetry, with 

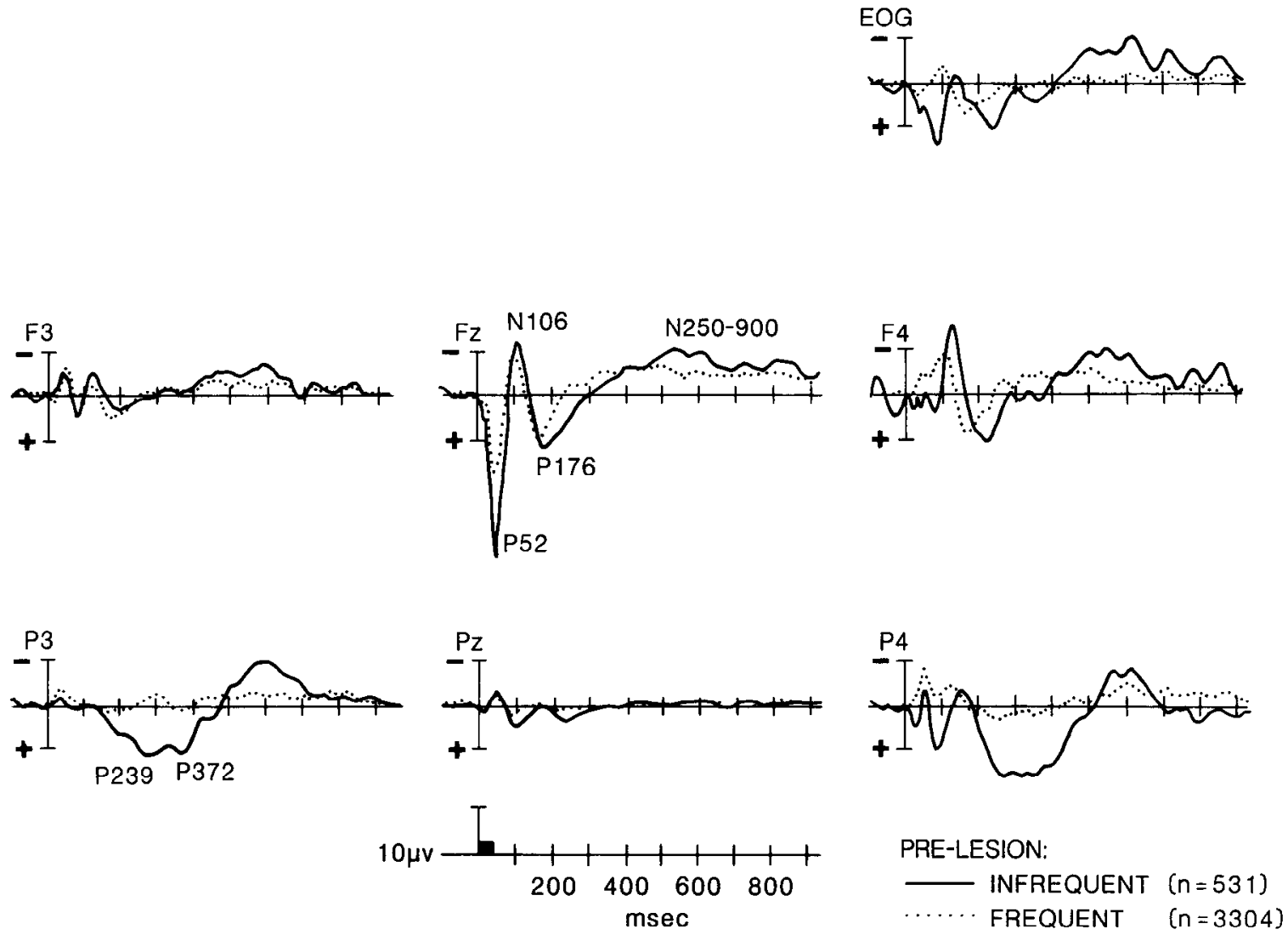

Figure 1. Grand average event-related potentials (ERPs) across 5 subjects recorded in response to frequent (90\%) and infrequent (10\%) tones (2 and $6 \mathrm{kHz}, 40 \mathrm{msec}$ duration, $60 \mathrm{~dB}$ above $\mathrm{nHL}$ ) presented once a second in random order. ERPs were recorded from these electrode sites twice a week for 4 weeks prior to locus coeruleus (LC) and dorsal bundle (DB) lesions. Recordings were obtained with an inion reference. Numbers in parenthesis indicate the number of trials in each average.

the differences observed mainly at lateral parietal and not lateral frontal electrodes [electrode $\times$ hemisphere, $F(1,4)=9.14, p<$ $0.04]$. Larger $P 372$ potentials were recorded over the right (1 103 msec- $\mu \mathrm{V})$ than over the left hemisphere $(497 \mathrm{msec}-\mu \mathrm{V})$ at lateral parietal sites.

Effects of repetitive recording sessions. $\mathrm{P} 239$ and $\mathrm{P} 372$ responses recorded at lateral parietal electrodes following either tone did not change significantly during the 4 weeks of prelesion recording (Fig. 3). No statistically significant effect of week was found $(p>0.51)$, nor was there a statistically significant operation by week interaction $(p>0.34)$.

\section{Postlesion ERPS}

Component distribution. Grand average (across all subjects) ERPs following frequent and infrequent tones in the postlesion condition are illustrated in Figure 4. P52, N106, P176, and N250900 continued to exhibit distinctive midfrontal distributions ( $p$ $<0.05$ ). As in the prelesion data, the anterior-to-posterior gradient for these components was significant along midline sites $(p<0.03)$. In contrast to the prelesion data, no localized brainsurface distribution was observed for P239 $(p=0.076)$. However, $\mathrm{P} 372$ responses remained larger over lateral parietal areas $(487 \mathrm{msec}-\mu \mathrm{V})$ than over lateral anterior $(103 \mathrm{msec}-\mu \mathrm{V})$ or midline $(48 \mathrm{msec}-\mu \mathrm{V})$ sites $(p<0.02)$.

Probability effects. P52 exhibited a sensitivity to stimulus probability similar to that observed in the prelesion data. P52 responses along midline sites were larger following infrequent than following frequent tones [probability $\times$ electrode, $F(5,20)$
$=3.46, p<0.04]$. Likewise, $\mathrm{N} 106$ responses along midline sites exhibited differential amplitudes following the 2 tones [probability $\times$ electrode, $F(5,20)=2.89, p<0.05]$. As in the prelesion data, P176 and N250-900 did not exhibit any effects of probability. P239 and P372, which exhibited significant differential responses to frequent and infrequent tones before the lesions, did not exhibit a statistically significant sensitivity to changes in stimulus probability after the lesions $(p>0.10)$.

Lateral asymmetries. P239 and P372 did not exhibit significant lateral asymmetries following lesions.

\section{Summary of lesion effects}

Comparisons between pre- and postlesion data indicated that lesions had no effect on the brain-surface topography of P52, N106, P176, or N250-900. Maximal amplitudes for these potentials were recorded over midfrontal cortex before and after lesions. Figure 5 illustrates the pre- and postlesion responses in the 90-10 blocks for P52, N106, P176, P239, and P372. These data indicate that the magnitude of the P52 component was reduced following lesions, but this reduction only approached significance $(p<0.08)$. In contrast, the reduction in the magnitude of $\mathrm{N} 106$ was significant [lesion, $F(1,4)=19.39, p<$ 0.02]. P176 was unaffected. P239 was significantly attenuated relative to prelesion measures [lesion, $F(1,4)=10.83, p<0.04$ ]. Neither P372 nor N250-900 were statistically different following the lesion in the $90-10$ blocks. However, in the $50-50$ blocks, both P372 and N250-900 were marginally affected by the lesion $(p<0.06)$. 
CB-F

SM12
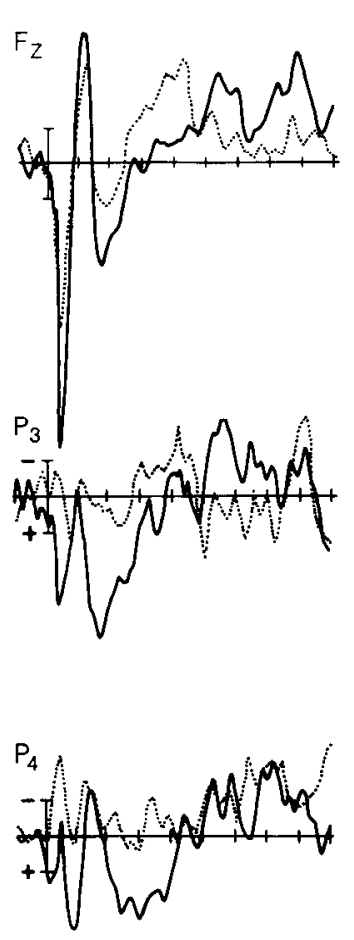

SM 16
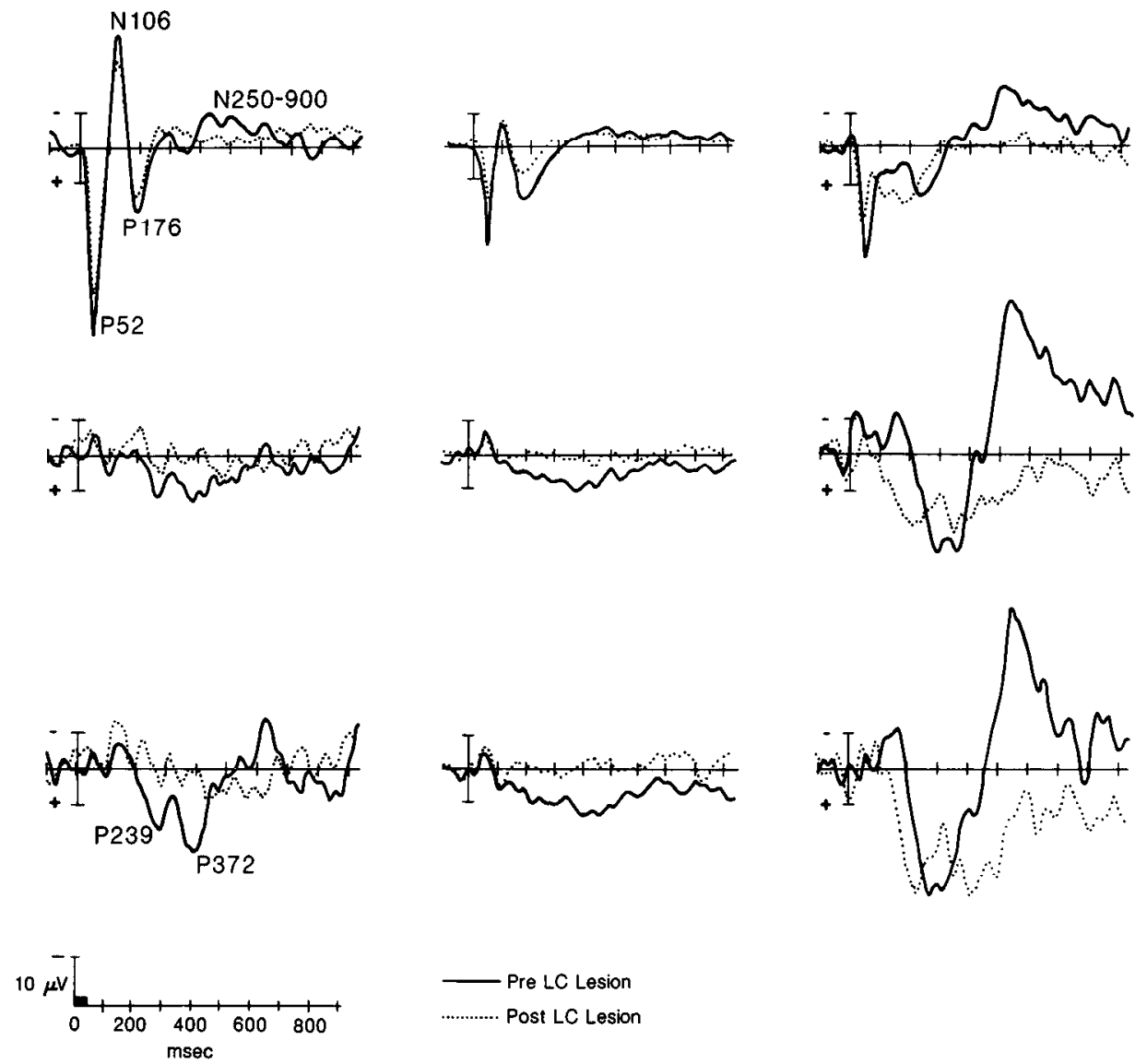
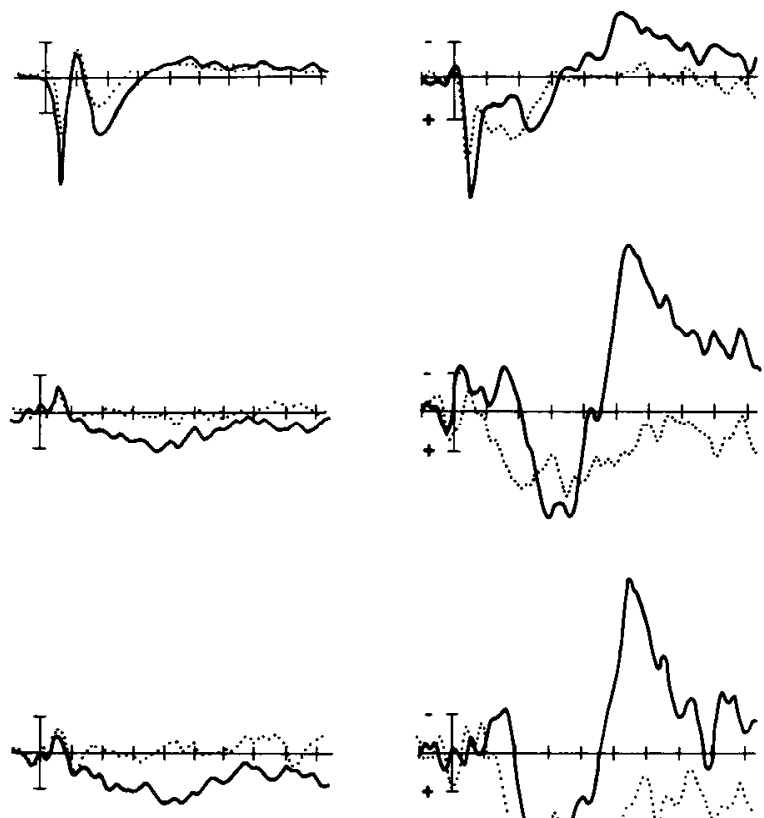

$\mathrm{F}$

SM14

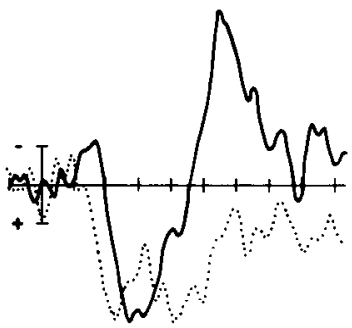

Pre LC Lesion
........... Post LC Lesion

Figure 2. Averaged ERPs from individual subjects recorded at Fz, P3, and P4 in response to infrequent (10\%) tones before and after lesions. Subjects (SM12, SM16, SM24) with cell-body and fiber lesions (CB-F) exhibited extensive lesions of the LC nucleus and DB fibers. Subject (SM14) with only fiber lesions (F) exhibited no LC cell body damage.
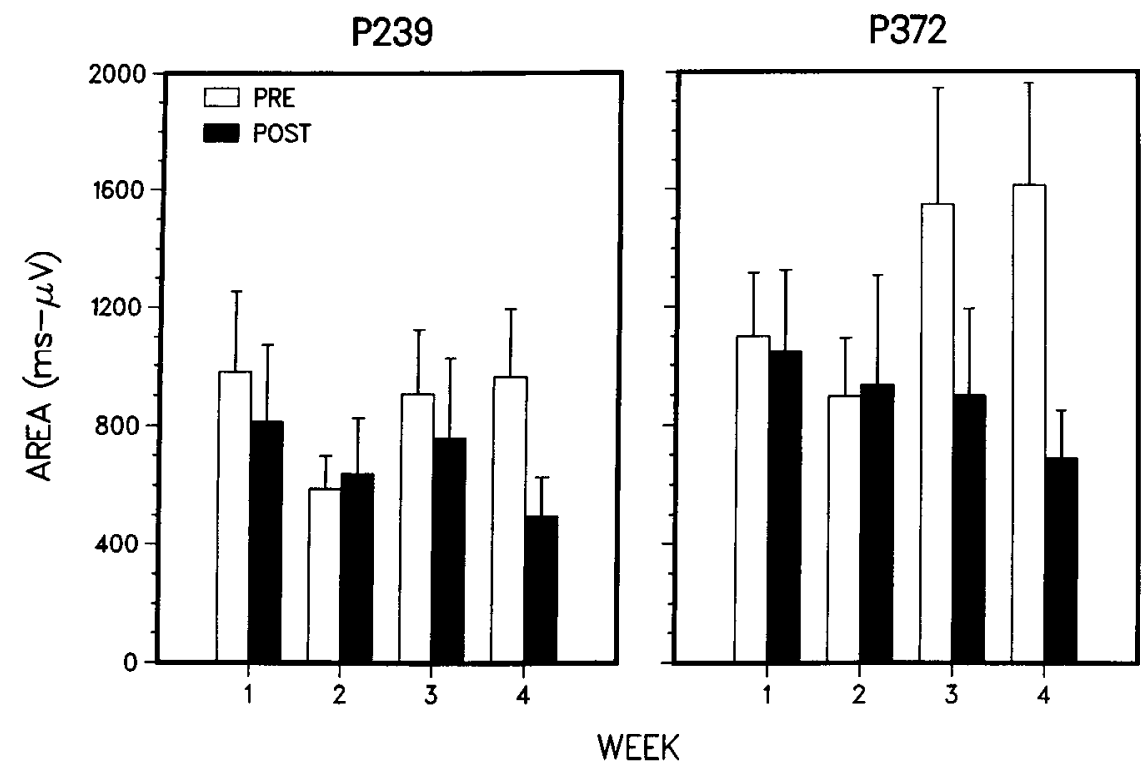

Figure 3. Mean P239 and P372 area recorded during 4 weeks before and after LC and DB lesions. Note the consistency of the prelesion area recorded across weeks for each component. 

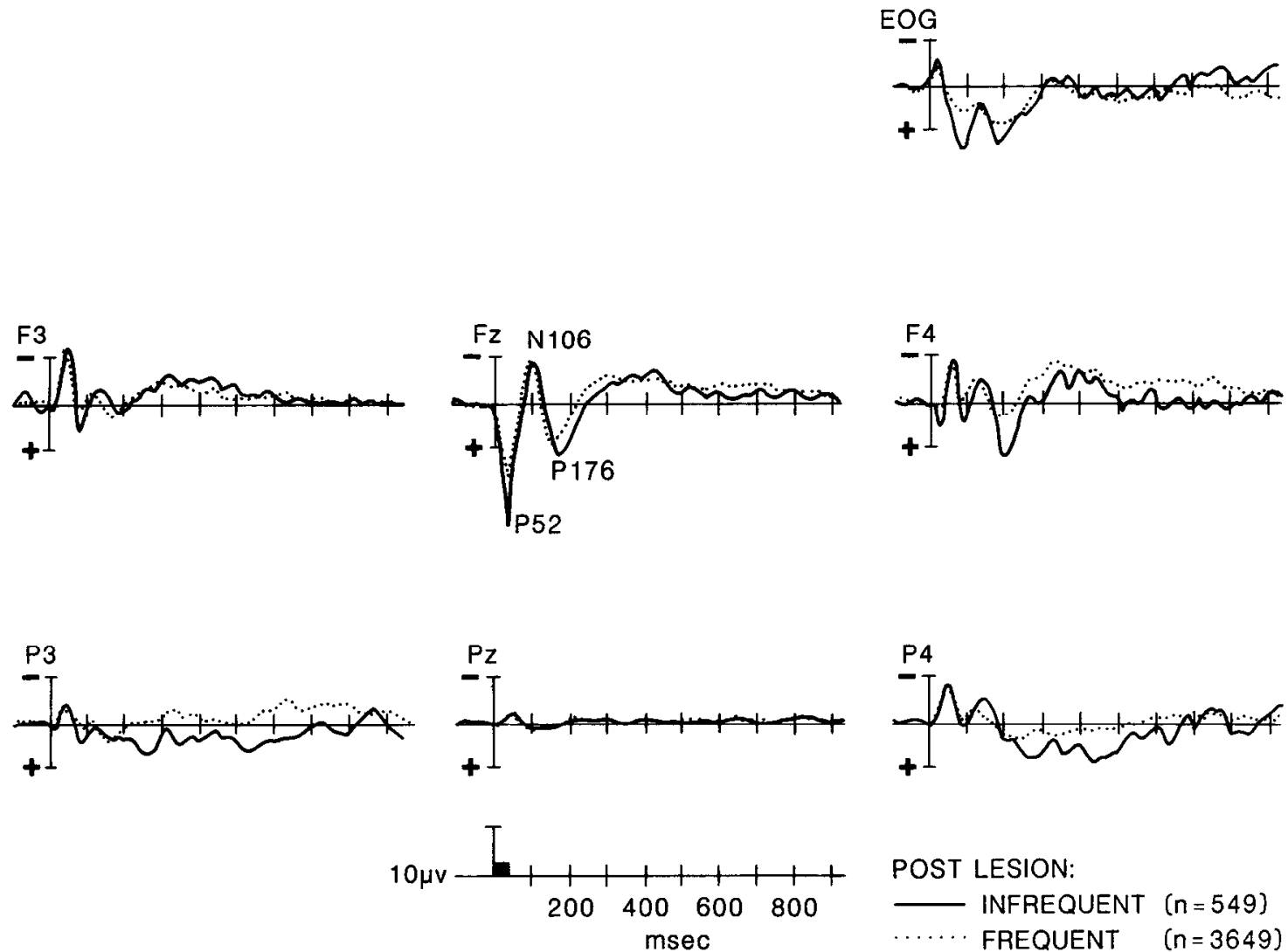

Figure 4. Grand average ERPs across 5 subjects recorded twice a week for 4 weeks following LC lesions. These ERPs were recorded under conditions identical to those for prelesion recordings.

\section{Evaluation of histology}

A schematic summary of the histological reconstructions of the lesions, based on Nissl-stained brain-stem sections, is shown in Figure 6. In 3 monkeys (SM12, SM16 and SM24), extensive bilateral electrolytic damage occurred to LC cell bodies. In the other 2 monkeys (SM14, SM19), there was either minimal or no apparent damage to the nucleus. In all monkeys, damage from the knife cut appears to have interrupted some fraction of the DB fibers. Panel $A$ of Figure 7 illustrates a sagittal section through the brain stem of a control monkey that has been stained for DBH. Panel $B$ displays a sagittal section also stained for DBH from a lesioned monkey (SM24) at approximately the same level, while panel $C$ shows an adjacent Nissl-stained section. As can be observed, the LC damage created by the electrolytic lesion was quite extensive in this monkey.
Figure 5. Mean area for P52, N106, P176, P239, and P372 in response to frequent $(90 \%)$ and infrequent $(10 \%)$ tones recorded at all electrode sites before and after LC and DB lesions.

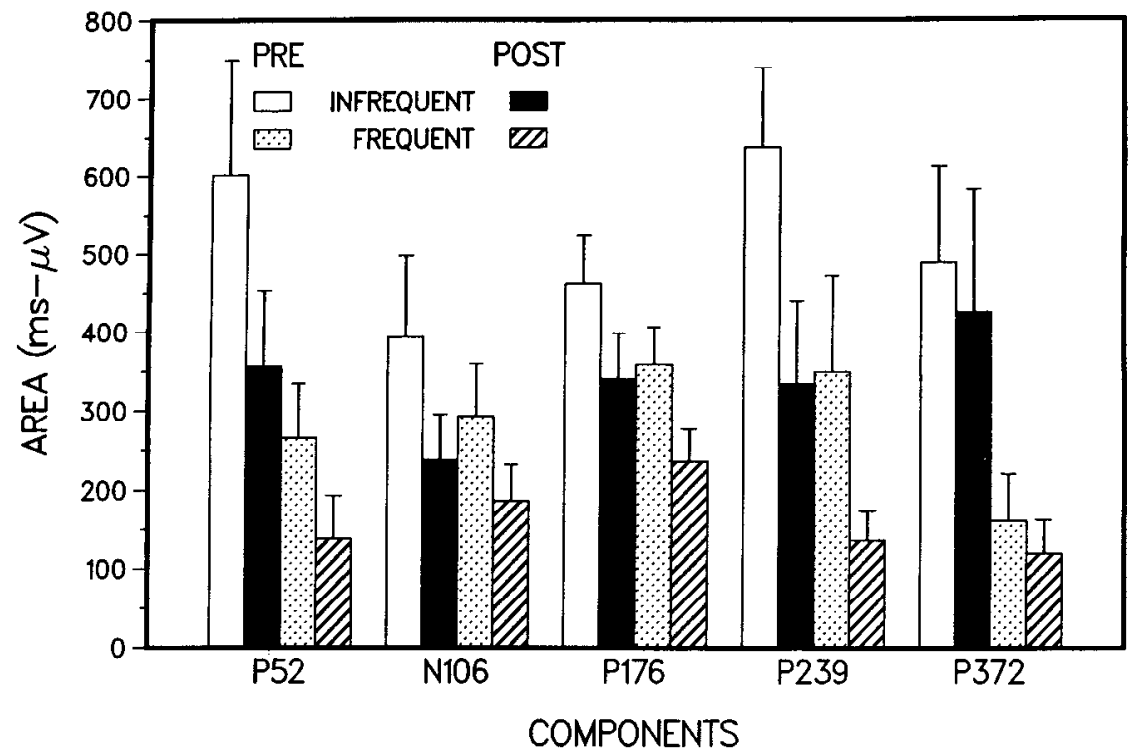


Squirrel

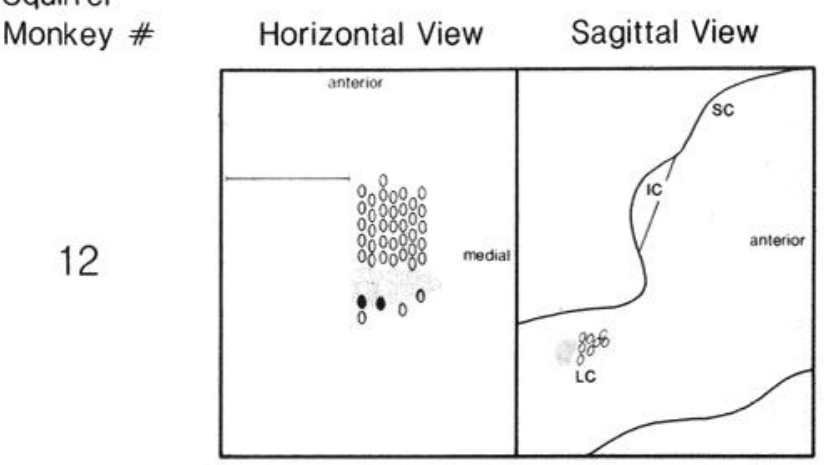

14

16

19
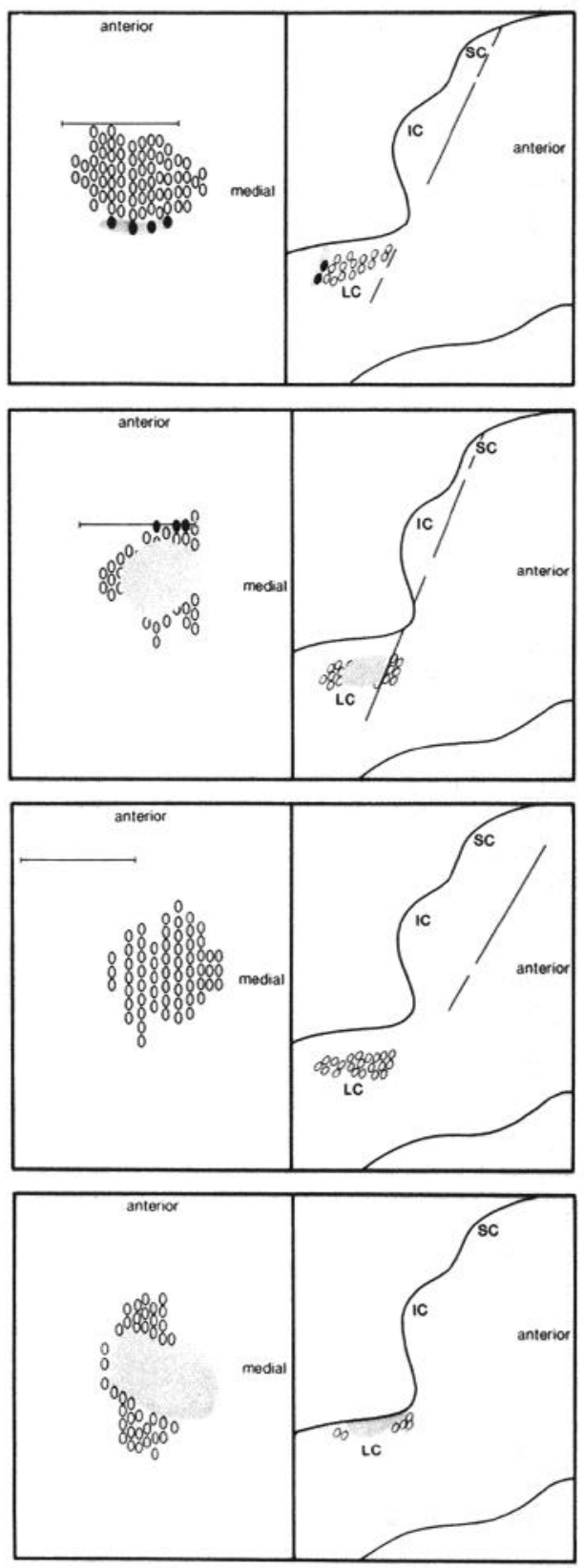

RIGHT HEMISPHERE
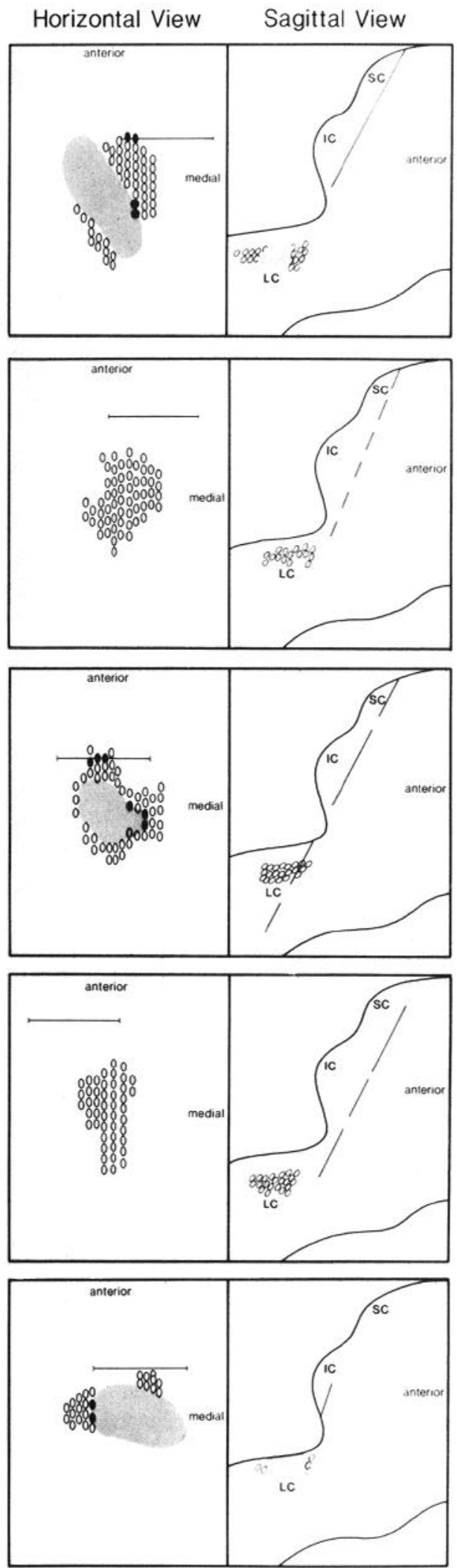

Figure 6. Schematic reconstructions based on 5-6 Nissl-stained sections through the brain stems showing damage caused by the electrolytic and knife cut lesions. The left (2) panels comprise a horizontal and sagittal view of the left hemisphere, the right (2) panels represent the right hemisphere. In the horizontal views, intact cell bodies are illustrated by open ovals, while dark ovals represent cells still visible but of abnormal appearance. Shading illustrates the area in which gliotic tissue was observed, and the horizontal line anterior to the nucleus represents the presumed mediolateral extent of the knife cut. In the sagittal views, the diagonal lines through the superior (SC) and inferior (IC) colliculi show the reconstructed electrode track made by the knife cut. 

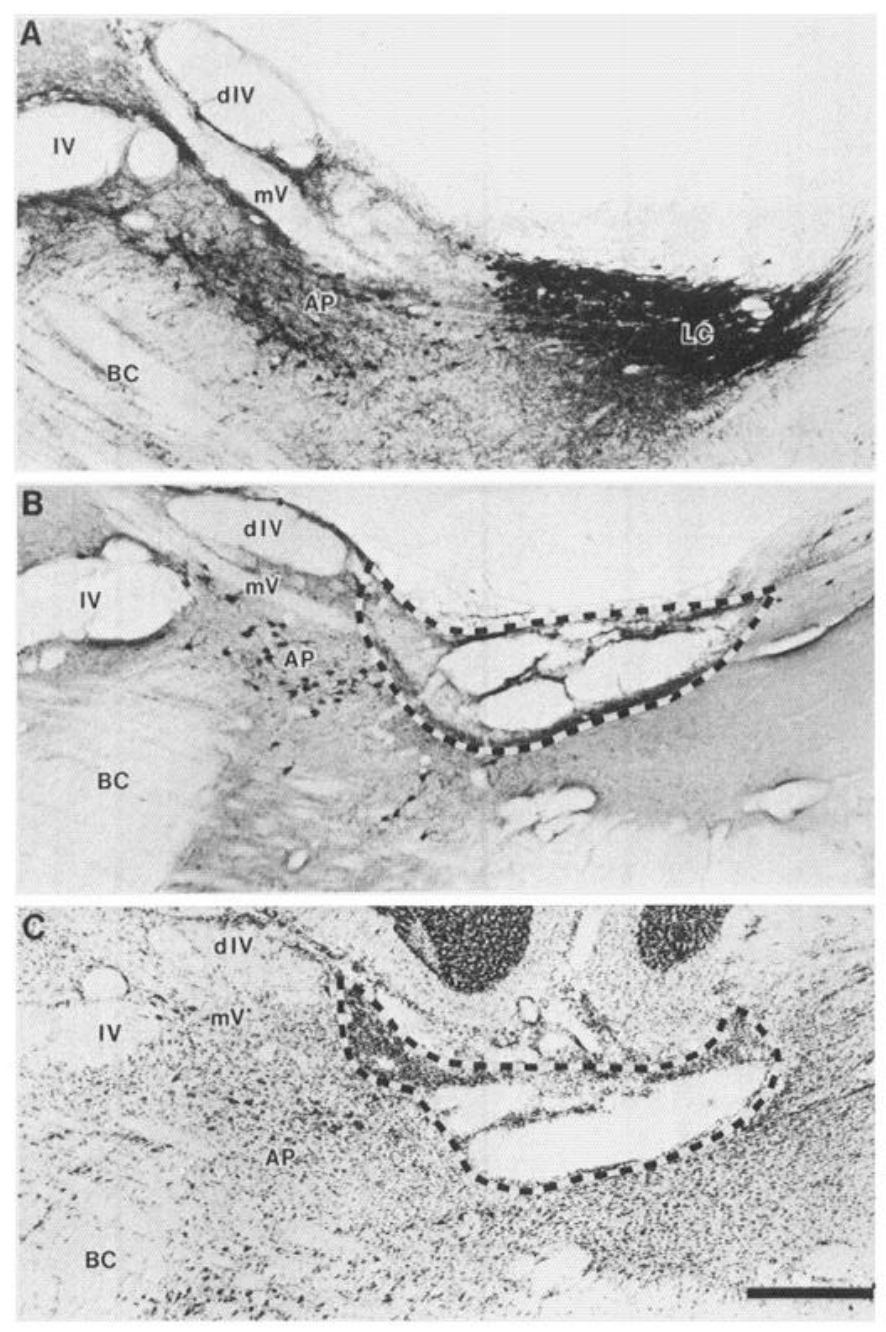

Figure 7. Sagittal sections through the brain stem of a control and a lesioned monkey (SM24). A, Section reacted with anti-dopamine-Bhydroxylase (anti-DBH) from a normal monkey shows the darkly labeled noradrenergic cells of the LC nucleus and its anterior pole $(A P)$. $B$, Section from lesioned monkey SM24, reacted with anti-DBH, is in approximately the same plane as the control section $(A)$. The dashed lines demarcate the boundaries of the electrolytic lesion. $C$, Adjacent Nissl-stained section also showing the extent of the electrolytic lesion. The dorsal and rostral portions of the sections are to the top and left, respectively. $B C$, brachium conjunctivum; $I V$, trochlear nerve; $d I V$, decussation of trochlear nerve; $m V$, tract of mesencephalic nucleus of trigeminus. (From Lewis et al., 1987.)

\section{DBH and TH immunoreactivity}

The efficacy of the lesions in forebrain areas was verified immunohistochemically in all animals by comparing $\mathrm{DBH}$ and TH immunoreactivity from lesioned animals with that of controls. As illustrated in Figure 8 for one lesioned monkey (SM24), there were decreases in neocortical DBH but not TH immunoreactivity relative to normal controls. Overall, there was a $60-80 \%$ decrease in DBH immunoreactivity in various cortical and subcortical areas in each of the 3 monkeys (SM12, SM16, and SM24) who exhibited cell body and DB fiber lesions. The remaining 2 monkeys (SM14, SM19), in which only DB fibers may have been damaged, exhibited more variability in $\mathrm{DBH}$ immunoreactivity, with some cortical areas showing slight decreases while others were relatively normal.

\section{Post hoc ERP analyses}

Because of differences in the location and extent of the lesions revealed by the histology and immunohistochemistry, post hoc analyses were carried out to determine the relationship between lesion efficacy and changes in P300-like component measures. The analyses consisted of 5-way ANOVAs with unequal Ns using factors of lesion-type (F and CB-F), lesion (pre and post), block (90-10 and 50-50), probability [Infrequent (low pitch) and Frequent (high pitch)], and electrode (Fz, Pz, F3, F4, P3, P4). Subjects ( 2 in the F and 3 in the CB-F condition) were nested within the group dimension. Repetition effects were analyzed using week (4) as an additional factor.

Effects of lesion type. Analyses of P52, P176, and N250-900 areas did not reveal any effects of, or interactions with, lesion type. In contrast, as illustrated in Figure 9, monkeys with damage to LC cell bodies and dorsal bundle fibers (CB-F) showed decreased P239 and P372 areas in the 90-10 blocks relative to their prelesion measures, while monkeys in which damage was restricted to DB fibers $(\mathrm{F})$ did not show such a marked decrease, [P239: lesion type $\times$ lesion $F(1,3)=10.44, p<0.05 ;$ P372: lesion type $\times$ lesion, $F(1,3)=49,57, p<0.01]$. Table 1 shows that monkeys with $40-70 \%$ of the LC damaged exhibited P239 and P372 area decreases greater than $60 \%$. In contrast, little ( $14 \%$ ) or no damage to the LC resulted in small decreases $(<42 \%)$ or even increases $(>100 \%)$ in area. A Spearman rank-order correlation coefficient based on all subjects' data indicated a statistically significant relationship between the extent of LC damage and the percentage decreases in area $\left(r_{s}=0.90, p<\right.$ $0.05)$. Analysis of the effects of repetitive recording sessions indicated that $\mathrm{CB}-\mathrm{F}$ animals showed a marked reduction in the overall magnitude of the positivity in the $200-500 \mathrm{msec}$ range as early as the first week of recording. This is illustrated in Figure 10 , which also shows the nonsignificant differences for subjects in the F group.

\section{Discussion}

\section{Prelesion ERPs}

The prelesion ERPs recorded in the present investigation closely resemble those previously reported in normal monkeys using passive paradigms (Neville and Foote, 1984; Pineda et al., 1987; Paller et al., 1988). These ERPs include a frontally dominant triphasic response (P52-N106-P176) in response to both tones. In addition, a long-latency, long-duration positivity is recorded in response to the infrequent tones embedded in the repetitive background. Previous studies have suggested that these monkey P300-like potentials recorded in untrained monkeys and in monkeys trained to make operant responses (Arthur and Starr, 1984; Paller et al., 1988; Pineda et al., 1988) are similar to the human P300 in terms of their polarity, latency, and duration. More important, they also resemble human P300 potentials in terms of their response to stimulus variables such as stimulus sequence, interstimulus interval, stimulus probability, and task relevance. Both human and monkey P300-like potentials consist of multiple subcomponents, are accompanied by temporally overlapping potentials, and increase in size as stimulus probability decreases.

However, unlike the human P3a, which is recorded in behaviorally passive subjects and which typically exhibits maximal amplitude over the frontal cortex (Roth, 1973; Squires et al., 1975; Snyder and Hillyard, 1976), monkey P300-like potentials in the present study exhibit maximal amplitude over 

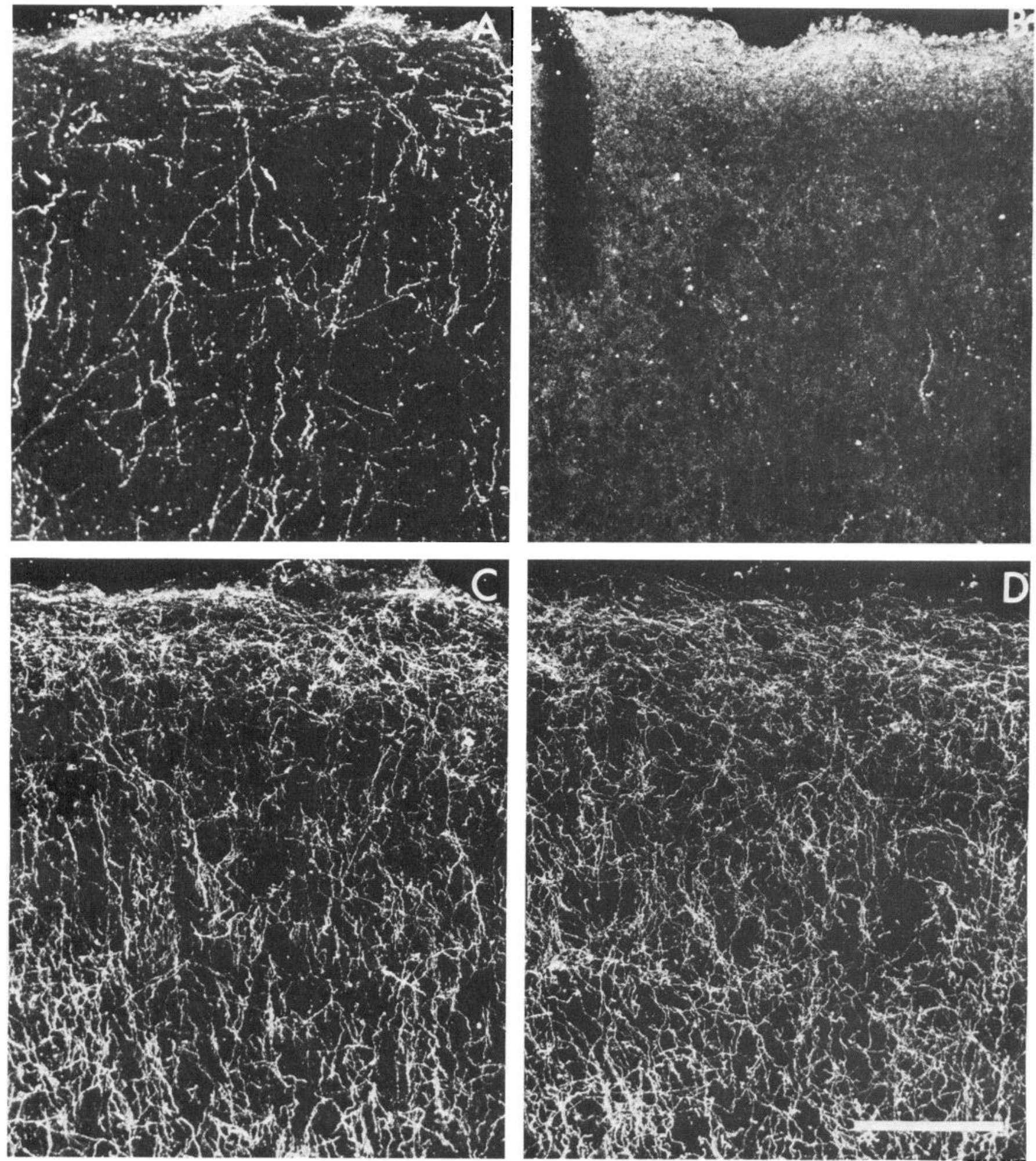

Figure 8. DBH $(A, B)$ and TH $(C, D)$ immunoreactivity in prefrontal cortex of a control (left column) and a lesioned monkey (right column). This was one of several cortical areas that were compared in all subjects. Note that compared with controls, DBH immunoreactivity was decreased following LC ablation. In contrast, TH immunoreactivity in this region was unchanged in the lesioned monkey compared with the control. Scale bar, $200 \mu \mathrm{m}$. (From Lewis et al., 1987.)

lateral parietal areas. These differences in topography may result from differences in the underlying brain geometry that characterize the 2 species (i.e., between the gyrencephalic human and lissencephalic squirrel monkey brain). Such differences in the extent of cortical folding may also account for lateral asymmetries exhibited by the monkey P300-like components, which tended to be larger over the right hemisphere. However, these asymmetries remain to be more fully investigated. Nonetheless, 
P239

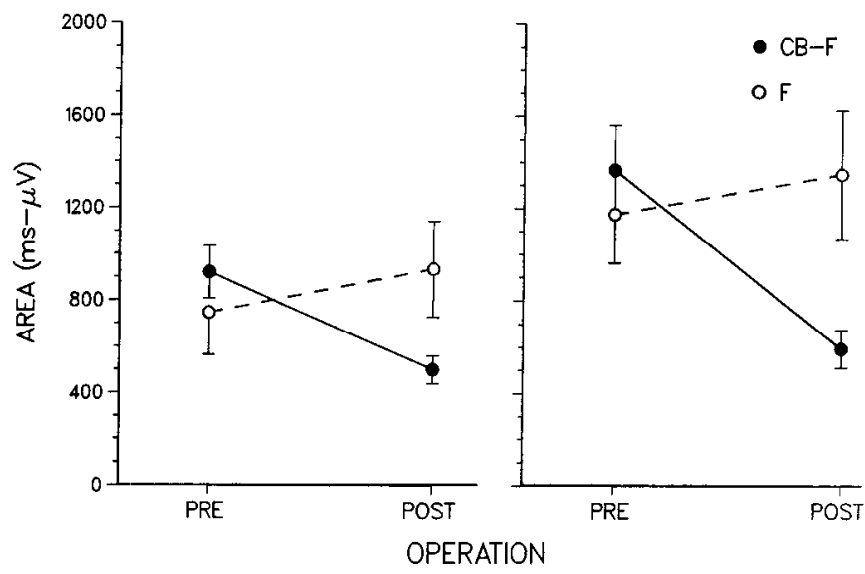

Figure 9. Effects of DB fiber lesions $(F)$ and combined cell-body and fiber $(C B-F)$ lesions on $\mathrm{P} 239$ and $\mathrm{P} 372$ areas. CB-F lesions resulted in significant decreases in both components in response to infrequent (lowpitch) tones, while $F$ lesions had no effect.

despite these differences in distribution, monkey P300-like potentials exhibit sufficient morphological and functional similarities to human P300 potentials to be considered analogous activity.

\section{Postlesion ERPS}

Brain-surface distribution. In lesioned animals, the brain-surface distribution of monkey long-latency, P300-like potentials was significantly altered. For example, the lateral parietal distribution and hemispheric asymmetry exhibited by P239 were not evident following lesions. Similarly, the lateral asymmetry exhibited by P372 was eliminated. However, postlesion P372 area measures were not statistically different from prelesion measures and P372 brain-surface distribution was not as markedly affected as P239. Significant P372 differences were found only when the extent of LC cell body lesions was taken into account in the analysis (see Post hoc ERP analyses). The brainsurface distributions of several other ERP components-such as P52, N106, P176, and N250-900-were not significantly al- tered following lesions. In general, these potentials continued to exhibit the same frontally dominant scalp distributions.

Stimulus probability. P239 and P372 responses, which were larger in response to infrequent $(10 \%)$ tones than to the frequent $(90 \%)$ tones before the lesion did not demonstrate this effect after the lesion. Thus, the systematic enhancement of P300 amplitude with changes in stimulus probability, which is also a property of monkey P300-like components (Arthur and Starr, 1984; Pineda et al., 1987; Paller et al., 1988), appears to be significantly disrupted by these lesions. In contrast, there were no lesion effects on the differential responses of P52 to the 2 tones, with this component being consistently larger in response to the infrequent tones. The same was true for N106, although N106 was significantly smaller overall after the lesions. Thus, these data suggest that the amplitude modulation of monkey P300-like components, resulting from variations in stimulus probability, may be mediated by corresponding differential responses in LC.

\section{Post hoc ERP analysis}

Post hoc analyses of the relationship between lesion efficacy and magnitude of P300-like components indicated that monkeys with damage to more than $40 \%$ of the LC nucleus combined with interruption of DB fibers showed an approximately 65$100 \%$ reduction in component area. Monkeys with little or no electrolytic damage to the nucleus, but with possible damage to DB fibers, exhibited either small decreases or increases in P300like component area. The data further indicated that P239 was much more affected regardless of the efficacy of the lesion, whereas P372 was significantly reduced only when damage to the NA-LC system was extensive. Since decreases in the magnitude of P300-like responses were quantitatively correlated with the degree of damage to the NA-LC system, it would suggest that P239 and P372 may be differentially sensitive to LC damage and forebrain NA depletion, with the earlier peak being more sensitive to slight damage to this system. These differential effects also suggest that P239 and P372 reflect different neural processes whose summated activity produces monkey P300. The relative specificity of the effects on monkey P300-like components and not on other measured peaks (with the exception of N106), argues against an overall change in arousal level,
Figure 10. Mean area of the positivity in the $200-500 \mathrm{msec}$ range recorded during 4 weeks before and after LC and DB lesions. Left, Bar graphs of the scores for CB-F animals; right, bar graphs for $F$ animals. Note that the reduction in area for $\mathrm{CB}-\mathrm{F}$ subjects is evident during the first week. No changes occur in the $F$ lesioned animals.
CB-F

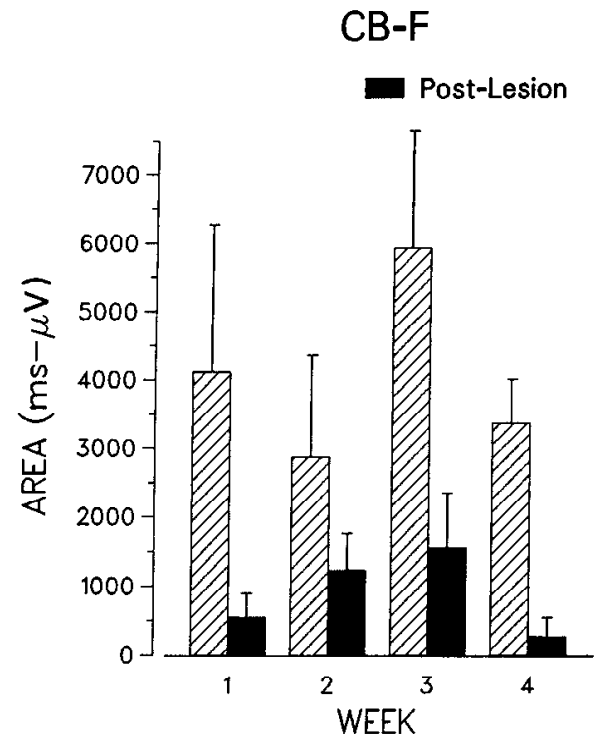

$\mathrm{F}$

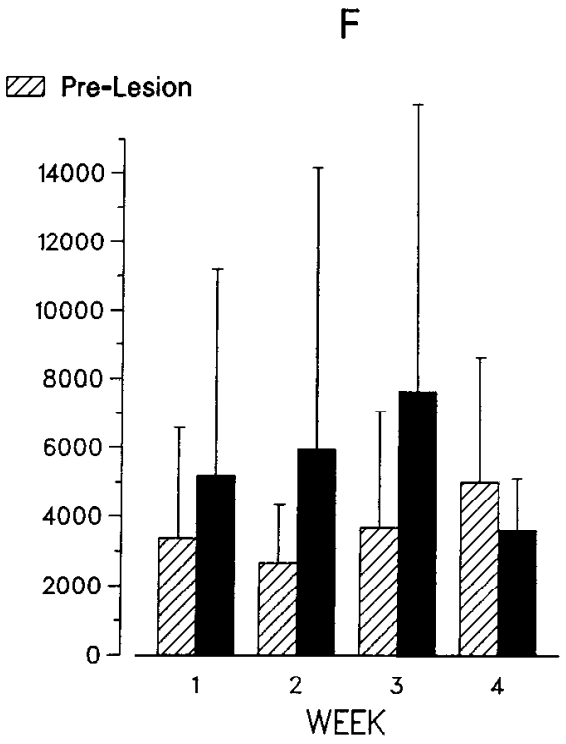


Table 1. Change in P239 and P372 area following lesions of the locus coeruleus

\begin{tabular}{|c|c|c|c|c|c|c|}
\hline \multirow[b]{3}{*}{ Subject } & \multicolumn{2}{|c|}{$\begin{array}{l}\text { Percent of LC } \\
\text { damaged }\end{array}$} & \multicolumn{4}{|c|}{ Percent change in component area } \\
\hline & \multirow{2}{*}{$\begin{array}{l}\text { Left } \\
\text { hemi- } \\
\text { sphere }\end{array}$} & \multirow{2}{*}{$\begin{array}{l}\text { Right } \\
\text { hemi- } \\
\text { sphere }\end{array}$} & \multicolumn{2}{|l|}{ P239 } & \multicolumn{2}{|l|}{ P372 } \\
\hline & & & $\overline{\mathrm{P3}}$ & $\mathrm{P} 4$ & P3 & P4 \\
\hline SM12 & 42 & 52 & -67 & -93 & -89 & -98 \\
\hline SM14 & 14 & 0 & +13 & +12 & +186 & +159 \\
\hline SM16 & 40 & 37 & -70 & -89 & -88 & -81 \\
\hline SM19 & 0 & 0 & -18 & -41 & +126 & -22 \\
\hline SM24 & 65 & 74 & -98 & -96 & -78 & -93 \\
\hline
\end{tabular}

which would be expected to produce more generalized ERP changes.

\section{Effects of repetitive recording sessions}

Decreases in the magnitudes of the P239 and P372 components may have occurred as a result of repeated sessions over time. The effects of habituation, for example, could conceivably account for such a decrease, especially considering that monkeys were not involved in performing a task. Nevertheless, no statistically significant differences in the magnitudes of the components were observed over the 4 weeks prior to the lesion. Postlesion effects depended on the extent of damage created by the lesions. CB-F animals demonstrated significant reductions in P300-like potentials from the first week, while F animals did not.

\section{Methodological considerations}

Several factors suggest caution in interpreting these data. First, despite the homogeneity of LC neurons and the small size of the electrolytic lesions, it is clear that areas in the trajectory of the microelectrode (e.g., cortex, colliculi), areas adjacent to the LC nucleus, and fibers of passage were also affected. Thus, systems other than the one targeted have been damaged, including systems possibly involved in the perception of sound. Second, the inherent variability in the extent of lesions plus the small number of subjects used reduces the power of any statistical evaluation. Several means of controlling for these factors are available and await future investigations. The nonspecificity of the lesions can be addressed by using noradrenergic neurotoxins such as 6-hydroxydopamine (6-OHDA), specific receptor agonists (e.g., yohimbine) or antagonists (e.g., clonidine; see Duncan and Kaye, 1986), or different trajectories into the brain stem. Concurrently, larger population samples would be needed to provide more robust evidence for a specific role of NA-LC in P300-like component generation or modulation.

\section{Possible neural mechanism of P300 generation and modulation}

The results of the present investigation are consistent with the hypothesis that NA-LC may be involved in the generation or modulation of $\mathrm{P} 300$-like activity, which has been related to novelty or stimulus mismatch detection and orienting (Squires et al., 1975; Snyder and Hillyard, 1976). The anatomical, physiological, and functional properties that characterize NA-LC support such a hypothesis. Anatomically, LC axons arising from the pontine brain stem are highly divergent, projecting into every major region of the neuraxis. They innervate functionally diverse cortical areas as they sweep tangentially across the cortex from frontal to occipital pole (Morrison et al., 1981, 1982b). This widely divergent pattern of cortical innervation exhibits, nonetheless, a spatial orderliness in regional and laminar specificity (Morrison et al., 1982a, 1984; Levitt et al., 1984), which suggests an underlying functional specificity. This is underscored by the fact that in the neocortex, cerebellum, and hippocampus a major portion of NA input is directed towards the output cells of these regions (Moore and Bloom, 1979). These highly divergent efferent projections provide a substrate whereby altered activity in LC source neurons could, with approximate simultaneity, influence activity in a number of cortical and subcortical regions. This spatially widespread but temporally defined activity would be consistent with the multiple-source hypothesis of P300 generation.

Physiologically, LC cells are phasically activated by a variety of arousing or alerting stimuli, including light flashes, tone pips, and somatosensory stimuli (Foote et al., 1980; Aston-Jones and Bloom, 1981). Tonic discharge rates vary from second to second depending on behavioral state. These changes anticipate by several hundreds of milliseconds subsequent cortical EEG changes indicating increased or decreased levels of alertness or attentiveness (Foote et al., 1980). The sensitivity of LC neurons to the arousing and attention-eliciting properties of multimodal stimuli, its sensitivity to trial-to-trial changes in these properties, its long latency, and long duration are congruent with the properties of P300-like components. Postsynaptically, NA has been found to reduce spontaneous activity in target cells to a greater extent than activity time-locked to an acoustic stimuli (Foote et al., 1975). These observations led to the proposal that NA may act on target neurons to enhance elicited activity relative to spontaneous activity, that is, to enhance the "signal-to-noise" characteristics of the cell (reviewed in Foote et al., 1983). Indeed, several subsequent studies have indicated that NA reduces background cellular activity while simultaneously enhancing stimulus-elicited excitation or inhibition (Woodward et al., 1979; Waterhouse and Woodward, 1980; Waterhouse et al., 1980). These investigations suggest that NA plays a modulatory role in the regulation of cortical responsiveness to sensory stimulation. Such actions may contribute to produce a behavioral state in which novel sensory stimuli are more effectively processed. This behavioral state may be a necessary precondition fo the elicitation of long-latency, P300-like potentials or may directly produce slow waves that are recorded as P300-like activity. Indeed, the decreased magnitude of monkey P300-like responses following lesions of the $\mathrm{LC}$ and ascending NA fibers is consistent with this hypothesis, although these results do not 
indicate whether NA-LC is both necessary and sufficient for the generation of P300-like activity.

Results from the present investigation are also consistent with behavioral studies involving lesions of the LC or DB fibers which have reported decreases in startle responses (Adams and Geyer, 1981), enhanced behavioral responsiveness to novelty (Britton et al., 1984), and increased distractability and increased exploratory behavior toward novel objects (Roberts et al., 1976; Oke and Adams, 1978; Koob et al., 1984). The demonstration that P300-like generation or modulation may be dependent upon the integrity of the NA-LC system could also link the observation that patients with clinical disorders such as dementia, alcoholism, schizophrenia, and affective disorders (Schildkraut and Kety, 1967; Dongen, 1981; Mair and McEntee, 1983) exhibit pathology of the NA-LC, with the demonstration that these conditions are also associated with altered P300s (Diner et al., 1985; Mirsky and Duncan, 1986; Polich et al., 1986). Finally, the fact that N106 was also affected by the lesions suggests that this component may reflect activity of the same substrates involved in P300-like generation and modulation.

Note added in proof: Since this paper was accepted for publication, it has been reported that bilateral lesions of the septal nuclei in cats, which result in marked AChE depletion in the hippocampus, cause the disappearance of P300-like potentials (Harrison et al., 1988). These results suggest that the functional integrity of the septo-hippocampal cholinergic system is critical in the modulation of these potentials. The relative importance of cholinergic and noradrenergic influences in the generation or modulation of monkey $\mathrm{P} 300$-like potentials remains to be determined.

\section{References}

Adams, L. M., and M. A. Geyer (1981) Effects of 6-hydroxydopamine lesions of locus coeruleus on startle in rats. Psychopharmacology 73: 394-398.

Arthur, D. L., and $\Lambda$. Starr (1984) Task-relevant late positive component of the auditory event-related potential in monkeys resembles P300 in humans. Science 223: 186-188.

Aston-Jones, G., and F. E. Bloom (1981) Norepinephrine-containing locus cocruleus neurons in behaving rats exhibit pronounced responses to non-noxious environmental stimuli. J. Neurosci. 1 : 887900.

Aston-Jones, G., S. L. Foote, and F. E. Bloom (1984) Anatomy and physiology of locus coeruleus neurons: Functional implications. In Norepinephrine: Clinical Aspects, M. G. Zeigler and C. R. Lake, eds., Williams \& Wilkins, Baltimore, MD.

Aston-Jones, G. F. Matthew, V. A. Pieribone, W. T. Nickell, and M. T. Shipley (1986) The brain nucleus locus coeruleus: Restricted afferent control of a broad efferent network. Science 234: 734-737.

Britton, D. R., C. Ksir, K. T. Britton, D. Young, and G. F. Koob (1984) Brain norepinephrine depleting lesions selectively enhance behavioral responsiveness to novelty. Physiol. Behav. 33: 473-478.

Callaway, E. (1975) Brain Electrical Potentials and Individual Psychological Differences, Grune \& Stratton, New York.

Courchesne, E. (1977) Event-related brain potentials: A comparison between children and adults. Science 197: 589-592.

Courchesne, E. (1978) Neurophysiological correlates of cognitive development: Changes in long-latency event-related potentials from childhood to adulthood. Electroencephalogr. Clin. Neurophysiol. 45: $468-482$.

Diner, B. C., P. J. Holcomb, and R. A. Dykman (1985) P300 in major depressive disorder. Psych. Res. 15: 175-184.

Donchin, E., W. Ritter, and W. C. McCallum (1978) Cognitive psychophysiology: The endogenous components of the ERP. In EventRelated Brain Potentials in Man, E. Callaway, P. Tueting, and S. H. Koslow, eds., Academic, New York.

Dongen, P. A. M. (1981) The human locus coeruleus in neurology and psychiatry. Prog. Neurobiol. 17: 97-139.
Duncan, C. C., and W. H. Kayc (1986) Effects of an alpha-2 adrencrgic agonist on information processing: An electrophysiological analysis. In Eighth International Conference on Event-Related Potentials of the Brain (EPIC VIII): Research Reports, J. W. Rohrbaugh, R. Johnson, $\mathrm{Jr}$., and R. Parasuraman, eds., Stanford, CA.

Foote, S. L., and F. E. Bloom (1979) Activity of norepinephrinecontaining locus coeruleus neurons in the unanesthetized squirrel monkey. In Catecholamines: Basic and Clinical Frontiers, E. Usdin, ed., Pergamon, New York.

Foote, S. L., and J. H. Morrison (1987) Extrathalamic modulation of cortical function. Annu. Rev. Neurosci. 10: 67-95.

Foote, S. L., R. Freedman, and A. P. Oliver (1975) Effects of putative neurotransmitters on neuronal activity in monkey auditory cortex. Brain Res. 86: 229-242.

Foote, S. L., G. Aston-Jones, and F. E. Bloom (1980) Impulsc activity of locus coeruleus neurons in awake rats and monkeys is a function of sensory stimulation and arousal. Proc. Natl. Acad. Sci. USA 77: 3033-3037.

Foote, S. L., F. E. Bloom, and G. Aston-Jones (1983) Nucleus locus coeruleus: New evidence of anatomical and physiological specificity. Physiol. Rev. 63: 844-914.

Gabriel, M., S. P. Sparenborg, and E. Donchin (1983) Macropotentials recorded from the cingulate cortex and anterior thalamus in rabbits during the "oddball" paradigm used to elicit P300 in normal human subjects. Soc. Neurosci. Abstr. 9: 1200.

Halgren, E., N. K. Squires, C. L. Wilson, J. W. Rohrbaugh, T. L. Babb, and P. H. Crandall (1980) Endogenous potentials generated in the human hippocampal formation and amygdala by infrequent events. Science 210: 803-805.

Harrison, J., and J. Buchwald (1985) Aging changes in the cat "P300" mimic the human. Electroencephalogr. Clin. Neurophysiol. 62: 227234.

Harrison, J. B., J. S. Buchwald, K. Kaga, N. J. Woolf, and L. Butcher (1988) 'Cat P300' disappears after septal lesions. Electroencephalogr. Clin. Neurophysiol. 69: 55-64.

Hillyard, S. A., and M. Kutas (1983) Electrophysiology of cognitive processing. Annu. Rev. Psychol. 34: 32-61.

Hillyard, S. A., and T. W. Picton (1979) Event-related potentials and selective information processing in man. In Progress in Clinical Neurophysiology, J. F. Desmedt, ed., Karger, Basel.

Hsu, S. M., L. Raine, and H. Fanger (1981) Use of avidin-biotinperoxidase complex (ABC) in immunoperoxidase techniques: A com-

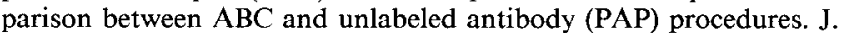
Histochem. Cytochem. 29: 557-580.

Koob, G. F., K. Thatcher-Britton, D. R. Britton, D. C. S. Roberts, and F. E. Bloom (1984) Destruction of the locus coeruleus or the dorsal NE bundle does not alter the release of punished responding by ethanol and chlordiazepoxide. Physiol. Behav. 33: 479-485.

Levitt, P., P. Rakic, and P. Goldman-Rakic (1984) Region-specific distribution of catecholamine afferents in primate cerebral cortex: Fluorescence histochemical analysis. J. Comp. Neurol. 227: 23-36.

Lewis, D. A., M. J. Campbell, S. L. Foote, M. Goldstein, and J. H. Morrison (1987) The distribution of tyrosine hydroxylase-immunoreactive fibers in primate neocortex is widespread but regionally specific. J. Neurosci. 7: 279-290.

Mair, R. G., and W. J. McEntee (1983) Korsakoff's psychosis: Noradrenergic systems and cognitive impairment. Behav. Brain Res. 9: 132 .

Markey, K. A., S. Kondo, L. Shenkman, and M. Goldstein (1980) Purification and characterization of tyrosine hydroxylase from a clonal pheochromocytoma cell line. Mol. Pharmacol. 17: 79-85.

Martineau, J., B. Garreau, C. Barthelemy, and G. Lelord (1984) Evoked potentials and P300 during sensory conditioning in autistic children. Ann. NY. Acad. Sci. 425: 362-369.

McCarthy, G., C. C. Wood, T. Allison, W. R. Goff, P. D. Williamson, and D. D. Spencer (1982) Intracranial recordings of event-related potentials in humans engaged in cognitive tasks. Soc. Neurosci. Abstr. 8: 976.

Mirsky, A. F., and C. C. Duncan (1986) Etiology and expression of schizophrenia: Neurobiological and psychosocial factors. Annu. Rev. Psychol. 37: 291-319.

Moore, R. Y., and F. E. Bloom (1979) Central catecholamine neuron systems: Anatomy and physiology of the norepinephrine and epinephrine systems. Annu. Rev. Neurosci. 2: 113-168.

Morrison, J. H., and S. L. Foote (1986) Noradrenergic and seroto- 
ninergic innervation of cortical, thalamic, and tectal visual structures in old and new world monkeys. J. Comp. Neurol. 243: 117-138.

Morrison, J. H., M. E. Molliver, R. Grzanna, and J. T. Coyle (1981) The intra-cortical trajectory of the coeruleocortical projection in the rat: A tangentially organized cortical afferent. Neuroscience 6: 139158.

Morrison, J. H., S. L. Foote, M. Molliver, F. E. Bloom, and H. G. Lidov (1982a) Noradrenergic and serotonergic fibers innervate complcmentary layers in monkey primary visual cortex: An immunohistochemical study. Proc. Natl. Acad. Sci. USA 79: 2401-2405.

Morrison, J. H., S. L. Foote, D. O'Connor, and F. E. Bloom (1982b) Laminar, tangential and regional organization of the noradrenergic innervation of monkey cortex: Dopamine-B-hydroxylase immunohistochemistry. Brain Res. Bull. 9: 309-319.

Morrison, J. H., S. L. Foote, and F. E. Bloom (1984) Laminar, regional, developmental, and functional specificity of monoaminergic innervation patterns in monkey cortex. Neurol. Neurobiol. 10: 61-75.

Neville, H. J., and S. L. Foote (1984) Auditory event-related potentials in the squirrel monkey: Parallels to human late wave responses. Brain Res. 298: 107-116.

O'Brien, J. H. (1982) P300 wave elicited by a stimulus-change paradigm in acutely prepared rats. Physiol. Behav. 28: 711-713.

O'Connor, T. A., and A. Starr (1985) Intracranial potentials correlated with an event-related potential, P300, in the cat. Brain Res. 339: 2738

Oke, A. F., and R. N. Adams (1978) Selective attention dysfunctions in adult rats neonatally treated with 6-hydroxydopamine. Pharmacol. Biochem. Behav. 9: 429-432.

Paller, K. A., S. Zola-Morgan, L. R. Squire, and S. A. Hillyard (1988) P3-like brain waves in normal monkeys and monkeys with medial temporal lesions. Behav. Neurosci. 102: 714-725.

Pfefferbaum, A., B. G. Wengrat, J. M. Ford, W. T. Roth, and B. S. Kopell (1984) The effects of age on event-related potentials. Psychophysiology 21: 312-326.

Pineda, J. A., S. L. Foote, and H. J. Neville (1987) Long-latency eventrelated potentials in squirrel monkeys: Further characterization of waveform morphology, topography, and functional properties. Electroencephalogr. Clin. Neurophysiol. 67: 77-90.

Pineda, J. A., S. L. Foote, H. L. Neville, and T. Holmes (1988) Endogenous event-related potentials in squirrel monkeys: The role of task relevance, stimulus probability, and behavioral response. Electroencephalogr. Clin. Neurophysiol. 70: 155-171.

Polich, J., L. Howard, and A. Starr (1985) Effects of age on the P300 component of the event-related potential from auditory stimuli: Peak definition, variation, and measurement. J. Gerontol. 40: 721-726.

Polich, J., C. L. Ehlers, S. Otis, A. J. Mandell, and F. E. Bloom (1986) P300 latency reflects the degree of cognitive decline in dementing illness. Electroencephalogr. Clin. Neurophysiol. 63: 138-144.

Pritchard, W. S. (1981) Psychophysiology of P300. Psychol. Bull. 89: 506-540.
Roberts, D. C. S., M. T. C. Price, and H. C. Fibiger (1976) The dorsal tegmental noradrenergic projection: Analysis of its role in maze learning. J. Comp. Physiol. Psychol. 90: 363-372.

Ritter, W., H. G. Vaughan Jr., and L. D. Costa (1968) Orienting and habituation to auditory stimuli: A study of short-term changes in average evoked responses. Electroencephalogr. Clin. Neurophysiol. 25: 550-556.

Roth, W. T. (1973) Auditory evoked responses to unpredictable stimuli. Psychophysiology 10: 125-137.

Roth, W. T., J. M. Ford, S. J. Lewis, and B. S. Kopell (1976) Effects of stimulus probability and task-relevance on event-related potentials. Psychophysiology 13: 311-317.

Roth, W. T., A. Pfefferbaum, T. B. Horvath, P. A. Berger, and B. S. Kopell (1980) P3 reduction in auditory evoked potentials of schizophrenics. Electroencephalogr. Clin. Neurophysiol. 49: 497-505.

Schildkraut, J. J., and S. S. Kety (1967) Biogenic amines and emotion. Science 156:21-30.

Snyder, E., and S. A. Hillyard (1976) Long-latency evoked potentials to irrelevant deviant stimuli. Behav. Biol. 16: 319-331

Squires N. K., K. C. Squires, and S. A. Hillyard (1975) Two varieties of long-latency positive waves evoked by unpredictable auditory stimuli in man. Electroencephalogr. Clin. Neurophysiol. 38: 387-401.

Squires, K., D. Goodin, and A. Starr (1978) Event related potentials in development, aging and dementia. In Human Evoked Potentials: Applications and Problems, D. Lehmann and E. Callaway, eds., Plenum, New York.

Sutton, S., M. Braren, J. Zubin, and E. R. John (1965) Evoked-potential correlates of stimulus uncertainty. Science $150: 1187-1188$.

Waterhouse, B. D., and D. J. Woodward (1980) Interaction of norepinephrine with cerebrocortical activity evoked by stimulation of somatosensory afferent pathways in the rat. Exp. Neurol. 67: 11-34.

Waterhouse, B. D., H. C. Moises, and D. J. Woodward (1980) Noradrenergic modulation of somatosensory cortical neuronal responses to iontophoretically applied putative neurotransmitters. Exp. Neurol. 69: $30-49$.

Wood, C. C., and G. McCarthy (1986) A possible frontal lobe contribution to scalp P300. In Eighth International Conference on EventRelated Potentials of the Brain (EPIC CIII): Research Reports, J. W. Rohrbaugh, R. Johnson, Jr., and R. Parasuraman, eds., Stanford, CA.

Wood, C. C., T. Allison, W. R. Goff, P. D. Williamson, and D. D. Spencer (1980) On the neural origin of P300 in man. Prog. Brain Res. 54: 51-56.

Woodward, D. J., H. C. Moises, B. D. Waterhouse, B. J. Hoffer, and R. Freedman (1979) Modulatory actions of norepinephrine in the central nervous system. Fed. Proc. 38: 2109-2116.

Yingling, C. D., and Y. A. Hosobuchi (1984) Subcortical correlate of P300 in man. Flectroencephalogr. Clin. Neurophysiol. 59: 72-76. 